\title{
Self-nanoemulsifying Drug Delivery System of Cilnidipine
}

\author{
Monica Raghavendra Prasad Rao*, Sayali Kulkarni, Ashwini Sonawane, Sayali Sugaonkar \\ Department of Pharmaceutics, AISSMS College of Pharmacy, Pune, Maharashtra, INDIA.
}

\begin{abstract}
Aim: Self-nanoemulsifying Drug Delivery Systems (SNEDDS) are physically stable, isotropic mixtures of oil, surfactant and co-surfactant. The turbulence generated by peristaltic movements of the GIT causes formation of oil-in-water (o/w) nano-emulsions upon dilution. The objective of this study was to improve solubility and oral bioavailability of Cilnidipine by formulating liquid-SNEDDS. Materials and methods: Capmul PG8 NF, Cremophor RH40, and Transcutol HP were selected as oil, surfactant, and co-surfactant. Ternary phase diagrams were constructed to evaluate the nanoemulsification region. A $3^{2}$ factorial design was employed to optimize L-SNEDDS with droplet size and drug release as responses. SNEDDS of CLN was evaluated for droplet size, self-emulsification time, in vitro drug release, ex-vivo permeation, pharmacokinetics and tissue distribution studies and stability studies. The optimized L-SNEDDS was converted into solid form using $\beta$-cyclodextrin nanosponges as adsorbents and evaluated in terms of micromeritics, drug content, scanning electron microscopy and powder X-ray diffraction. Results: The optimized batch exhibited droplet size of $23.70 \mathrm{~nm}$, and in vitro drug release of $95.24 \%$ in $60 \mathrm{~min}$. The in-vivo studies revealed nearly 5.53 folds increase in $\mathrm{AUC}_{0-\infty}$ of optimized batch of liquid SNEDDS compared to CLN which can be credited to increase in solubility and dissolution rate. Conclusion: In vivo studies revealed improved pharmacokinetic properties which were attributed to greater surface area and lymphatic absorption leading to circumvention of hepatic first pass metabolism.
\end{abstract}

Key words: Cilnidipine, $3^{2}$ factorial designs, Nanosponges, solid SNEDDS, Oral bioavailability.

\section{INTRODUCTION}

The number of new chemical entities with prolonged receptor binding characteristics, higher therapeutic efficacy but minimal aqueous solubility is expanding. This leads to reduced membrane permeability and poor and erratic bioavailability. ${ }^{1}$ Various approaches to overcome these challenges include salt formation, ${ }^{2}$ micronizatio, ${ }^{3}$ solid dispersions, ${ }^{4}$ complexation with cyclodextrins, ${ }^{5}$ self-emulsifying formulations, ${ }^{6}$ and liposomes. ${ }^{7}$

Lipid-based drug delivery systems represent a diverse group of formulations which include several classes of excipients (e.g.triglyceride oils, mixed glycerides, lipophilic surfactants, hydrophilic surfactants and water-soluble co-solvents). ${ }^{8}$ Pouton et al. ${ }^{9}$ suggested a lipid formulation classification system (LFCS) based on in-vivo fate of components of formulation. The physico-chemical properties of the drug play a key role to select the best LFCS. Type III formulations comprising mixture of hydrophilic surfactants and/or hydrophobic surfactants/ solvents are most effective for hydrophobic drugs such as lacidipine, ${ }^{10}$ efavirenz, ${ }^{11}$ docetaxol, ${ }^{12}$ atorvastatin. ${ }^{13}$ This type gives rise to self-emulsifying drug delivery systems which have greater acceptability as they have a plethora of advantages which include thermodynamically stable formulations with improved bioavailability and circumvention of first pass metabolism. ${ }^{14}$
Submission Date: 16-02-2021; Revision Date: 06-05-2021; Accepted Date: 02-07-21

DOI: 10.5530/ijper.55.3.138 Correspondence: Dr. Monica RP Rao

Department of Pharmaceutics, AISSMS College of pharmacy, Pune-411001, Maharashtra INDIA.

Phone no: +919822916490 Email: monicarp_6@hotmail. com

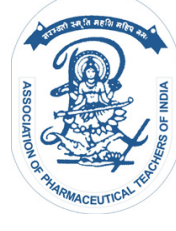

www.ijper.org 
Self nanoemulsifying drug delivery systems (SNEDDS) are physically stable, isotropic mixtures of oil, surfactant and co-surfactant. The turbulence generated by peristaltic movements of the gastrointestinal tract (GIT) causes formation of oil-in-water (o/w) nano-emulsions, upon dilution with GI fluids. ${ }^{15}$ SNEDDS presents the drug in solubilized form with droplet size less than $100 \mathrm{~nm}$ which provides a large interfacial area for drug absorption, providing greater chemical and enzymatic stability as also inhibiting P-glycoprotein (P-gp) mediated drug efflux. ${ }^{16}$ These liquid systems, however suffer from problems such as leaching from gelatin capsules, incompatibility with soft gelatin capsules in addition to penetration into hard jelly. ${ }^{17}$ Solid SNEDDS have been designed to overcome these problems wherein liquid SNEDDS (L-SNEDDS) is converted into solid form by spray drying, extrusion spheronization or adsorption. Spray drying was used to convert ezetimide L-SNEDDS to solid form with silicon dioxide. ${ }^{18}$ Loratadin SNEDDS was converted into solid form by extrusion spheronization using lactose, microcrystalline cellulose, silicon dioxide and Na- crosscarmelose. ${ }^{19}$ Aerosil 200 was used to prepare solid self-nanoemulsifying drug delivery system (S-SNEDDS) of nifedipine by adsorption process. ${ }^{20}$

Cilnidipine (CLN) is chemically 3-(2-methoxyethyl) 5-(2E)-3-phenylprop-2-en-1-yl 2,6-dimethyl-4-(3-nitrophenyl)1,4-dihydropyridine-3,5-dicarboxylate. It is categorized as calcium channel antagonist accompanied with L-type and $\mathrm{N}$-type calcium channel blocking functions. Its dose is $20 \mathrm{mg}$ once a day, partition coefficient $(\log \mathrm{P})$ is 4.7 and ionization constant ( $\mathrm{pKa}$ ) of 11.39. CLN displays high protein binding and is primarily metabolized by both liver and kidney. It is rapidly metabolized by liver microsomes by dehydrogenation process. It is a BCS Class II drug with aqueous solubility and oral bioavailability of $5.66 \times 10^{-3} \mathrm{mg} / \mathrm{ml}$ and $13 \%$ respectively. ${ }^{21}$ As per literature review, solid dispersion, ${ }^{22}$ and liquisolid, ${ }^{23}$ polymeric nanoparticles, ${ }^{24}$ microemulsion, ${ }^{25}$ and solid lipid nanoparticles, ${ }^{26}$ have been used to enhance solubility and oral bioavailability of CLN. Bakhle et al. ${ }^{27}$ developed solid self emulsifying system of CLN using Capryol 90 as oil phase, Tween 80 as surfactant and Transcutol HP as cosurfactant but in vivo studies were not performed. In the present study, SNEDDS of CLN was developed using full factorial design and evaluated for droplet size, self-emulsification time, in vitro drug release, ex vivo permeation, pharmacokinetics and tissue distribution studies. The optimized L-SNEDDS was converted into solid formusing various inert adsorbents and evaluated in terms of micromeritics, drug content, scanning electron microscopy and powder X-ray diffraction.

\section{MATERIALS AND METHODS}

CLN was gifted by Alembic Pharma, India. Capmul MCM, Capmul PG-8 NF, Capmul 908P, AccononCC6, AccononMC8, Captex 100, Captex 355 were gifted by Abitec Corporation, USA. Cremophor RH 40 was gifted by Mohini Organics, Mumbai. Tween 80, Brij 30, Transcutol HP were purchased from S.D. Fine Chemicals, Mumbai, India. All other reagents and solvents were of analytical grade or HPLC grade.

\section{Selection of oil and surfactants}

Preliminary studies were carried out to select suitable Selection of oil and surfactants based on their solubilization ability for the drug. An excess amount of CLN was added to $2 \mathrm{ml}$ of each vehicle and stirred continuously for $48 \mathrm{~h}$ at $37^{\circ} \mathrm{C}$ in an orbital shaker (Remi Laboratories, CIS-24BL). The dispersions were centrifuged at $5000 \mathrm{rpm}$ for 20 mins. The supernatant was diluted with methanol and the concentration of CLN in the solution was analyzedby U.V spectroscopy (LAB INDIA UV $3000^{+}$) at $240 \mathrm{~nm}^{28}$

\section{Drug-excipient compatibility studies}

Mixtures of CLN with oil, surfactant and cosurfactant in 1:1 ratio were stored in stoppered glass vials and exposed to temperature of $40^{\circ} \mathrm{C}$ and $75 \%$ relative humidity for 1 month to assess any unwanted reactionbetween drug and excipients. Analysis of samples was done by Fourier transform infrared (FTIR) spectrophotometer (JASCO FTIR-460 Plus). The IR spectrum of the physical mixture was compared with those of pure drug and excipients. Peak matching was done to detect any appearance or disappearance of peaks. ${ }^{29}$

\section{Construction of pseudo-ternary phase diagram}

Based on solubility of drug in various oils and surfactants, ternary phase diagrams were constructed using water titration method in order to identify self nano-emulsifying region. Isotropic mixtures of surfactant and cosurfactant $\left(\mathrm{S}_{\text {mix }}\right)$ were prepared in ratios of 1:0.25, 1:0.50, 1:0.75 and 1:1 using cyclomixer (Remi laboratories, CM101) and heated to $40^{\circ} \mathrm{C}$ to solubilize the drug. Oil- $\mathrm{S}_{\text {mix }}$ ratios of $1: 9,2: 8,3: 7,4: 6,5: 5,6: 4,7: 3,8: 2$ and $9: 1$ were prepared in vials and distilled water (DW) was added drop wise till appearance of turbidity. Volume of water at which turbidity appeared was noted as end point. 
Phase diagrams were constructed by using Chemix software (CHEMIX School Ver. 4.01 software, MN, USA.). ${ }^{30}$

\section{Preparation of liquid-SNEDDS (L-SNEDDS)}

L-SNEDDS were prepared by incorporating $10 \mathrm{mg}$ drug into mixtures of accurately weighed quantity of $S_{\text {mix }}$ and oil in glass beaker. Components were mixed using a magnetic stirrer (Remi RQT-124A) followed by vortexing using cyclomixer (Remi laboratories, CM101) and heated on a water bath (Metalab) $40^{\circ} \mathrm{C}$ to form a homogenous mixture. The L-SNEDDS were observed for homogeneity, change in color and transparency or phase separation during storage at $37 \pm 2^{\circ} \mathrm{C} .{ }^{31}$

\section{Experimental design}

Full factorial design $\left(3^{2}\right)$ was used to evaluate effect associated with independent variables on L-SNEDDS. Based upon preliminary studies, quantity of $S_{\text {mix }}$ and oil were selected as independent variables. The levels of $S_{\text {mix }}$ (factor A) were varied from 1, 5.5 and $7 \mathrm{~g}$, while levels of oil (factor B) selected were 1, 2 and $3 \mathrm{~g}$ (weight ratios). The 12 batches (F1-F12) generated by the software (Design Expert software version 11.0) by applying 4 center points per block and these were analyzed for droplet size (Y1) and cumulative percent drug release in $60 \mathrm{~min}$ (Y2). Constraints were provided to software to select the optimized batch. ${ }^{32}$

\section{Characterization of factorial batches Droplet size (Y1)}

The droplet size and zeta potential was determined by dynamic light scattering principle. The L-SNEDDS formulation was diluted 250 times with distilled water (DW) under gentle stirring. After achieving equilibrium, the droplet size was analyzed by ZetaSizer (Malvern, UK, ZS 90). ${ }^{33}$

\section{Cumulative \% drug release in $60 \min (Y 2)$}

The drug release study of CLN SNEDDS was carried out by using dialysis technique. ${ }^{34}$ A length of $4 \mathrm{~cm}$ of dialysis tubing (Dialysis membrane 70, HIMEDIA; MWCO 12,000-14,000 daltons; pore size $2.4 \mathrm{~nm}$ ) was cut and a cylindrical pocket-type sample holder was fashioned out of it by tying both ends. The pocket was tied to the paddle of USP Type II dissolution apparatus and placed in $900 \mathrm{ml}$ of $0.1 \mathrm{~N} \mathrm{HCl}$ with stirring at $50 \mathrm{rpm}$ and temperature of $37^{\circ} \mathrm{C}$. Aliquots of $5 \mathrm{ml}$ were taken out at $15 \mathrm{~min}$ time intervals for $1 \mathrm{~h}$ and suitably diluted with $0.1 \mathrm{~N} \mathrm{HCl}$. Every time the volume of the eachaliquot was replaced using fresh dissolution medium. These samples were analyzed for the CLN present in the dissolution medium at the corresponding time by UV-visible spectrophotometer at $240 \mathrm{~nm}$.

\section{Characterization of optimized batch Self-emulsification time}

Optimized L-SNEDDS $(1 \mathrm{ml})$ was added in $500 \mathrm{ml}$ of DW in glass beaker with gentle agitation using a magnetic stirrer (Remi laboratories, $1 \mathrm{MLH}$ ) to $50 \mathrm{rpm}$, at $37^{\circ} \mathrm{C} \pm$ $2{ }^{\circ} \mathrm{C}$. The process of self-nano emulsification was visually examined by the time taken by formulation to form a clear emulsion. ${ }^{35}$

\section{Percent transmittance studies}

Optimized batch of L-SNEDDS (1 ml) was mixed with $100 \mathrm{ml}$ of DW till formation of a homogenous solution. Percent transmittance was measured by double beam UV-visible spectrophotometer (LAB INDIA, UV $\left.3000^{+}\right)$at $560 \mathrm{~nm}$ using distilled water as a blank. ${ }^{36}$

\section{Cloud point measurement}

The optimized batch of L-SNEDDS was diluted with DW in the ratio of 1:500 and placed in a water bath with a gradual rise in temperature. The temperature at which sudden appearance of turbidity occurred was noted as the cloud point. ${ }^{37}$

\section{Viscosity determination}

The viscosity of optimized batch of L-SNEDDS was determined before and after dilution using a Brookfield Viscometer (Brookfield Viscometer RVDV Pro II) using spindle RV-6 at $100 \mathrm{rpm}$ at $25 \pm 0.5^{\circ} \mathrm{C} .{ }^{38}$

\section{Preparation of S-SNEDDS}

The optimized L-SNEDDS was converted into solid form by adsorption technique using various adsorbents such as microcrystalline cellulose, calcium carbonate, magnesium carbonate, Aerosil 200 and nanosponge of beta cyclodextrin crosslinked with diphenyl carbonate ( $\beta$-CD nanosponges). The optimized L-SNEDDS was added dropwise on to the solid adsorbents in various ratios (1:1, 1:2, 1:3 and 1:4). After each addition, the mixture was homogenized by trituration in glass mortar to ensureevendistribution. The selection of adsorbent was based on micromeritic properties of S-SNEDDS. ${ }^{39}$

\section{Characterization of S-SNEDDS Micromeritic properties}

Micromeritic properties of S-SNEDDS such asangle of repose by fixed funnel free standing cone method, Carr's Index (CI) and Hausner's ratio were determined. ${ }^{40}$ 


\section{Powder X- ray Diffraction}

Powder X-ray diffraction pattern of CLN and S-SNEDDS was investigated by using powder X-ray diffractometer (X-ray generator Philips, Netherlands, PW 1729, Savitribai Phule University, Pune). The X-rays were $\mathrm{Ni}$-filtered $\mathrm{CuK} \alpha 1$ radiation with $40 \mathrm{kV}$ and $30 \mathrm{~mA}$ over $0-100^{\circ} / 2 \theta^{41}$

\section{Scanning electron microscopy}

The surface morphology of $\beta-C D$ nanosponge and S-SNEDDS were inspected by electron microscope (JEOL, JSM-6360A, Diya Labs, and Mumbai) at a voltage of $15 \mathrm{keV}$. The particles were fixed on the carbon stub using double-sided adhesive tape and then made electrically conductive by platinum coating, in a vacuum, with a thin layer of platinum $(10 \AA)$, for $100 \mathrm{~s}$ and at $30 \mathrm{~W}$. The samples were lightly spread on a double adhesive tape stuck to an aluminum stub. The stubs were then coated with platinum to a thickness of about $10 \AA$ under an argon atmosphere using a gold sputter module in a high-vacuum evaporator. Afterwards, the stub containing the coated samples was placed in the scanning electron microscope chamber. ${ }^{42}$

\section{Drug content estimation}

S-SNEDDS equal to $10 \mathrm{mg}$ of the drug was dispersed in $250 \mathrm{ml}$ of methanol, sonicated (Labman, LMUC-2) to dissolve the drug. The dispersion was centrifuged (Remi RM-12CBL) at $3000 \mathrm{rpm}$ for $15 \mathrm{~min}$. The supernatant was suitably diluted and examined at $240 \mathrm{~nm}$ by UV-visible spectrophotometer. ${ }^{43}$

\section{Ex vivo permeation studies}

Ex vivo permeation studies were performed to study the absorption of drug across intestinal membrane by everted intestinal sac method. ${ }^{44}$ The goat intestine was everted over a glass rod and placed in a dish containing Krebs-Henseleit bicarbonate buffer at $37^{\circ} \mathrm{C} .{ }^{45}$ The everted intestine was mounted on a modified permeation apparatus consisting of a U-tube glass chamber (diameter $=2.5 \mathrm{~cm})$ with a break in one arm to facilitate the mounting of the everted intestine. This assembly was placed in the dissolution vessel such that the inside of the U-tube served as the intestinal lumen and the dissolution vessel served as the serosal compartment. Krebs solution $(900 \mathrm{ml})$ was used as dissolution media. Optimized batch was subjected to permeation studies at $37^{\circ} \mathrm{C}$ and $50 \mathrm{rpm}$ stirring speed in the USP type II dissolution apparatus. Aliquots were collected at different time points (for $6 \mathrm{~h}$ ) and analyzed by $\mathrm{UV}$-visible spectrophotometer at $240 \mathrm{~nm}$.

\section{Pharmacokinetics studies}

Permission was taken from institutional animal ethics committee (IAEC) (Research proposal number CPCSEA/IAEC/PT-09/02-2K19) for carrying out in vivo, tissue distribution studies and their guidelines were followed in the course of the study. The protocol for the experimentation was duly approved by the animal ethics committee. The comparative in vivo pharmacokinetic study was carried out with 18 male Wistar rats (weighing 200-250 g) which were divided randomly into three groups (control, standard, and test) with six rats in each group. The animals were fasted overnight $(12 \mathrm{~h})$ prior to the dosing.

Pure drug suspensionwas prepared by adding CLN in DW with $0.5 \%$ sodium carboxy methylcellulose as suspending agent. ${ }^{46}$ Pure drug suspension and L-SNEDDS (equivalent to $1 \mathrm{mg} / \mathrm{kg}$ dose) were given orally to the animals using 18-gauge oral feeding cannula. The rats were anaesthetized using diethyl ether, and $0.5 \mathrm{ml}$ blood sample was withdrawn from the retro-orbital vein of rat at 0 (pre-dose), 0.5, 1, 2, 3 and $4 \mathrm{~h}$, collected in micro centrifuge tubes containing ethylene diamine tetra acetic acid (EDTA) as anticoagulant. The samples were centrifuged (Remi Laboratories, RM-124A) at $5000 \mathrm{rpm}$ for $10 \mathrm{~min}^{24}$ The plasma was separated and stored at $-20^{\circ} \mathrm{C}$ until further analysis. The plasma was mixed with $1 \mathrm{ml}$ methanol to precipitate the proteins and the samples were vortexed for $2 \mathrm{~min}$ followed by centrifugation at $5000 \mathrm{rpm}$ for $10 \mathrm{~min}$. Supernatant was then separated and reconstituted using $200 \mu \mathrm{l}$ mobile phase. The supernatant was analyzed by bioanalytical reverse phase high performance liquid chromatography (RP-HPLC) method (Agilent, 1120 compact LC) with methanol: acetonitrile $(50: 50 \% \mathrm{v} / \mathrm{v})$ as mobile phase at flow rate $1 \mathrm{ml} / \mathrm{min}$ and $\mathrm{C}_{18}$ column $(250 \mathrm{~mm} \times 4.6$ $\mathrm{mm}$ i.d., $5 \mu \mathrm{m}$ particle size). The detection wavelength of drug in plasma was set at $240 \mathrm{~nm}$. The method was validated for linearity, precision (intra-day and inter-day), accuracy, specificity, limit of detection (LOD), limit of quantification (LOQ), and robustness. Pharmacokinetic parameters like peak plasma concentration $\left(\mathrm{C}_{\max }\right)$, time to achieve $\mathrm{C}_{\max }\left(\mathrm{T}_{\max }\right)$, and area under plasma concentration $\left(\mathrm{AUC}_{0-\infty}\right)$ were determined. The data were considered as statistically significant at $P<0.05$ (ANOVA studies). GraphPad Prism 8.1 version 2 software was used for ANOVA studies. ${ }^{47}$

\section{Tissue distribution studies}

The pure drug suspension and L-SNEDDS were administered to the rats using 18-gauge oral feeding cannula at a dose of $1 \mathrm{mg} / \mathrm{kg}$. Two hours after administration, 
the rats were anesthetized with diethyl ether. The liver, kidney and mesenteric lymph nodes were excised from one rat in standard and test each group. The collected tissues were then rinsed with normal saline and homogenizedusing homogenizer (Bio-lab, BL244) by adding mobile phase as mentioned previously at $50 \mathrm{rpm}$ for $5 \mathrm{~min}$. The dispersions were centrifuged at $5000 \mathrm{rpm}$ for $5 \mathrm{~min}$ and supernatant was analyzed by bioanalytical method. ${ }^{48}$

\section{Stability studies}

Optimized L-SNEDDS was subjected to physical and chemical stability studies for 3 months at $40^{\circ} \mathrm{C} \pm 75 \%$ RH (Remi, CHM 6 S) and evaluated for appearance, color, particle size, zeta potential and poly dispersibility index and drug content at an interval of $0,1,2$, and 3 months. ICH Q1A (R2) guidelines were followed for stability studies. ${ }^{49}$

\section{RESULTS AND DISCUSSION}

\section{Solubility studies}

Solubility of CLN in lipid carrier is main parameter for selection of components for developing SNEDDS (Figure 1). ${ }^{50}$ The oil improves solubility and fraction of lipophilic drugs transported through the intestinal lymphatic system and drug loading capability, thus increasing absorption through the GIT. ${ }^{51}$ The oil, surfactant and cosurfactant were selected based on their higher solubilization potential for the drug. Capmul PG-8 NF was selected as the oily phase, Cremophor RH 40 as surfactant and Transcutol HP as the cosurfactant. Partition coefficient of CLN $(\log \mathrm{P})$ is reported as $4.6^{52}$ which was indicative of its high lipophilicity whereas the HLB of Capmul PG-8 is reported to be in the range of $5-6,{ }^{53}$ which also points to its lipophilic nature. Thus we may infer that the oil, being lipophilic has greater solubilization capacity for the lipophilic

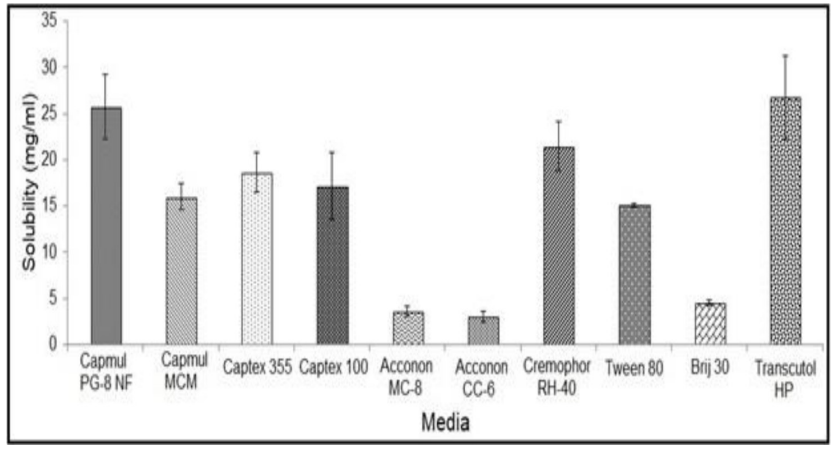

Figure 1: Solubility of CLN in various surfactants, cosurfactants and oils $(n=3$, mean \pm SD). drug. ${ }^{54}$ Besides this Capmul PG-8 is a medium chain triglyceride (MCT) with 11 carbonsand it is reported that MCTs have better capacity for dissolving hydrophobic drugs due to their medium chain length and betterfluiditythanlong chain triglyceride (LCT). ${ }^{55}$ In addition, MCTs are easy to nano-emulsify as compared to LCTs. Cremophor RH40 is polyoxyl-40 hydrogenated castor oil with HLB 14-16. It has been widely used in lipid based formulations due to its amphiphilic nature and ability to dissolve large quantities of drugs as also its good self nano-emulsification property. ${ }^{56}$ Transcutol HP was selected as co-surfactant due to its ability to dissolve large quantity of drug $(26.77 \mathrm{mg} / \mathrm{ml})$ and high adeptness for emulsification of oil..$^{57}$ As per the mixed film theory, addition of co-surfactant with surfactant resulted in a stronger $\mathrm{o} / \mathrm{w}$ interfacial barrier film leading to smaller droplet size. ${ }^{58}$

\section{Drug-excipient compatibility studies}

FTIR spectra of physical mixture of CLN, Cremophor RH40, Transcutol HP and Capmul PG-8 NF, the major peaks of CLN were observed at wavenumbers $3374.82 \mathrm{~cm}^{-1}, 3070.12 \mathrm{~cm}^{-1}, 2925.48 \mathrm{~cm}^{-1}, 1922.68 \mathrm{~cm}^{-1}$, $1617.98 \mathrm{~cm}^{-1}, 1498.42 \mathrm{~cm}^{-1}, 1045.23 \mathrm{~cm}^{-1}$ and $700.03 \mathrm{~cm}^{-1}$. By comparing the spectra of CLN and its physical mixture, it was observed that all the peaks lie in their appropriate range. No spectral changes were observed which indicated that there was no interaction between CLN and other excipients. ${ }^{59}$

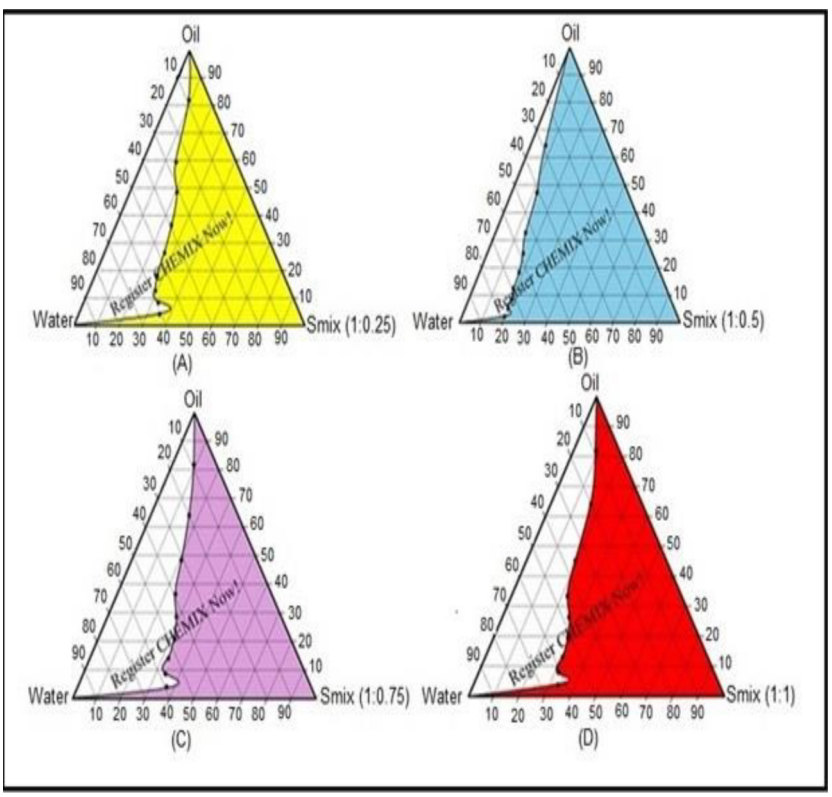

Figure 2: Pseudo ternary phase diagrams $A=S_{\text {mix }}(1: 0.25)$, $B=S_{\text {mix }}(1: 0.5), C=S_{\text {mix }}(1: 0.75),(D)=S \operatorname{mix}(1: 1)$. 


\section{Pseudo ternary phase diagram}

Selection of oil, $S_{\text {mix }}$, and oil to $S_{\text {mix }}$ ratio, play an important role in the formation of the nano-emulsion. Among four ternary phase diagrams constructed with $S_{\text {mix }}$ ratios of 1:0.25, 1:0.5, 1:0.75 and 1:1, nano-emulsion region for $S_{\text {mix }} 1: 0.5$ of Cremophor RH40:Transcutol HP was found to be larger than other $S_{\text {mix }}$ ratios (Figure 2). The region of emulsification was identified from area enclosedwithin the solid line. At the oil-water interface, mixed film was formed by the use of $S_{\text {mix }}$ which results in the reduction in droplet size and better stability of nanoemulsion. ${ }^{60}$ The chain length difference between surfactant and cosurfactant plays major role in selfemulsification process. Transcutol HP is a C6 diethylene glycol monoethylether ${ }^{61}$ whereas Cremophor $\mathrm{RH} 40$ consists of a 12 carbon fatty acid chain forming the lipophile esterified by polyoxyethylene groups totaling 40 numbers. Thus Transcutol, being much smaller in molecular size is able to effectively intersperse between the Cremophor molecules at the oil-waterinterface leading to the formation of an efficient mixed film barrier.Amount of cosurfactant to be included is thus critical in the barrier film. In this study, a smaller nanoemulsion region at ratio of 1:0.25 could indicate that amount of cosurfactant is not sufficient to form a strong barrier film. At $S_{\text {mix }}$ ratios of 1:0.75 and 1:1, it may be inferred that amount of cosurfactant is more than that required to form a mixed film. Hence excess cosurfactant may be forming micelles independently which are not as effective barriers as compared to mixed films, leading to larger size droplets.

\section{Experimental design}

Full factorial design $\left(3^{2}\right)$ was used for the optimization of L-SNEDDS by varying its factors such as amount of oil (factor A) and the amount of $S_{\text {mix }}$ (factor B). The levels were varied as 1,2 and $3 \mathrm{~g}$ of $\mathrm{A}$ and $4,5.5$ and 7 $\mathrm{g}$ of $\mathrm{B}$. The experimental batches were optimized using Design Expert software version 11.0. The 12 batches (F1-F12) predicted by the software were analyzed for responses such as droplet size $(\mathrm{nm})(\mathrm{Y} 1)$ and cumulative percent drug release $(\%)(\mathrm{Y} 2)(n=3)$ (Table 1). ${ }^{62}$

\section{Droplet size}

Droplet size is one of the main characteristics affecting in vivo fate of emulsions. The droplet size of emulsion also affects the rate and extent of drug release. Smaller the droplet size, the larger is the surface area provided for drug absorption (Figure 3)..$^{13}$

Droplet size $=+49.52+6.04 \mathrm{~A}-60.80 \mathrm{~B}-3.38 \mathrm{AB}+$

$$
3.28 \mathrm{~A}^{2}-46.55 \mathrm{~B}^{2}
$$

The droplet size of factorial batches was found to be between 20.41 to $174.86 \mathrm{~nm}$. The linear effect of the amount of $S_{\text {mix }}$ (B) was found to be significant $(p<0.05)$. The negative coefficient implied that an increase in the amount of $S_{\text {mix }}$ (B) led to a decrease in droplet size (Y1). The quadratic effect of amount of $S_{\text {mix }}\left(B^{2}\right)$ was also found to be significant $(p<0.05)$ having negative coefficient thus ratifying the role of $S_{\text {mix }}$ in reduced droplet size and its stability. The low droplet size with increasing $S_{\text {mix }}$ concentration could be attributed to the ultra low interfacial tension due to the mixed barrier film at the $\mathrm{o} / \mathrm{w}$ interface. The effect of the amount of oil (A) was

\begin{tabular}{|c|c|c|c|c|c|}
\hline & Factor A & Factor B & Response $\left(Y_{1}\right)$ & Response $\left(Y_{2}\right)$ & \multirow{2}{*}{$\begin{array}{c}\text { Zeta potential } \\
(\mathrm{mV})\end{array}$} \\
\hline $\begin{array}{l}\text { Formulation } \\
\text { code }\end{array}$ & $\begin{array}{c}\text { A: Amount of Oil } \\
(g)\end{array}$ & $\begin{array}{c}\text { B: Amount of } \\
S_{\text {mix }}(g)\end{array}$ & ${ }^{*}$ Droplet Size $(\mathrm{nm})$ & $\begin{array}{l}{ }^{*} \text { Cumulative } \% \\
\text { Drug Release (\%) } \\
\text { (at } 60 \text { minutes) }\end{array}$ & \\
\hline $\mathrm{F} 1$ & 3 & 4 & $159.9 \pm 4.25$ & $78.72 \pm 1.57$ & $-28.53 \pm 1.7$ \\
\hline $\mathrm{F} 2$ & 2 & 5.5 & $57.51 \pm 2.52$ & $85.52 \pm 2.15$ & $-20.1 \pm 0.95$ \\
\hline F3 & 2 & 7 & $29.94 \pm 5.50$ & $93.69 \pm 2.21$ & $-14.53 \pm 0.9$ \\
\hline F4 & 1 & 5.5 & $26.17 \pm 2.26$ & $82.03 \pm 2.50$ & $-25.53 \pm 0.92$ \\
\hline F5 & 3 & 5.5 & $33.4 \pm 1.66$ & $81.66 \pm 2.90$ & $-22.4 \pm 1.21$ \\
\hline F6 & 2 & 5.5 & $61.84 \pm 4.64$ & $84.36 \pm 1.68$ & $-17.06 \pm 2.36$ \\
\hline $\mathrm{F} 7$ & 3 & 7 & $20.41 \pm 0.55$ & $96.41 \pm 2.30$ & $-19.9 \pm 0.98$ \\
\hline F8 & 1 & 7 & $48.89 \pm 2.86$ & $90.19 \pm 2.13$ & $-8.20 \pm 2.17$ \\
\hline F9 & 1 & 4 & $174.86 \pm 5.30$ & $75.8 \pm 2.47$ & $-11.29 \pm 1.97$ \\
\hline F10 & 2 & 4 & $129.3 \pm 2.68$ & $83.58 \pm 2.71$ & $-2.91 \pm 0.65$ \\
\hline F11 & 2 & 5.5 & $51.91 \pm 7.45$ & $85.14 \pm 3.24$ & $-11.33 \pm 1.13$ \\
\hline F12 & 2 & 5.5 & $59.73 \pm 4.00$ & $85.91 \pm 3.31$ & $-4.83 \pm 0.88$ \\
\hline
\end{tabular}




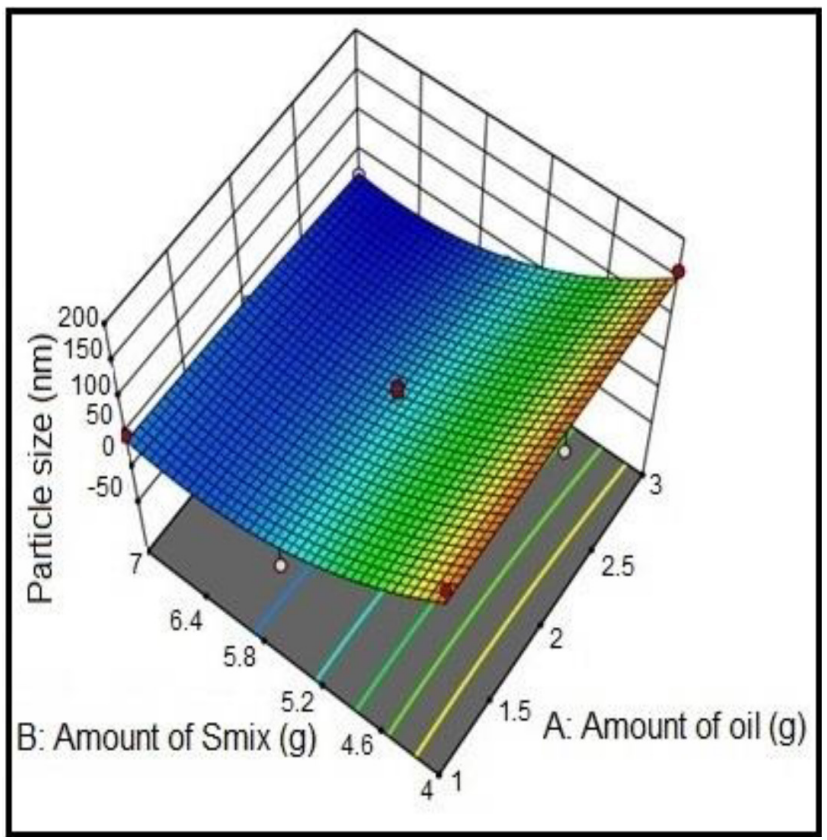

Figure 3: Response surface plot for droplet size. $(n=3$, mean $\pm \mathrm{SD})$.

found to be significant $(p<0.05)$ with positive coefficient indicating an increase in droplet size (Y1) with an increase in the amount of oil (A). However the low coefficient of A suggests that amount of oil is not as important as amount of $S_{\text {mix }}$ in controlling and stabilizing droplet size.

Zeta-potential was found to be in the range of -2 to $-28 \mathrm{mV}$ for all the formulations. The negative zeta potential of all batches could be attributed to the ionization of surface functional groups of oil or surfactant especially the free carboxylic acid groups. However, the low negative zeta potentials of L-SNEDDS could be due to the shifting of the plane of shear at which zeta potential is measured, to a larger distance from the oil surface due to steric stabilization of the oil droplets. This however does not affect the stability of the nanosystem. ${ }^{63}$

\section{Cumulative percent drug release in $60 \mathrm{~min}(\mathrm{Y} 2)$}

The factorial batches were subjected to in vitro dissolution studies using dialysis membrane. Drug release profile is an important parameter of any drug delivery system as it affects the onward journey of the drug molecules, affecting its pharmacokinetic profile (Figure 4 and 5). The following polynomial equation was generated by Design Expert software:

Cumulative percent drug release $=+85.23-1.46 \mathrm{~A}+$ $7.03 \mathrm{~B}+0.8250 \mathrm{AB}-3.37 \mathrm{~A}^{2}+3.42 \mathrm{~B}^{2}$

Cumulative percent drug release (Y2) of factorial batches of L-SNEDDS was found to be between 75.8

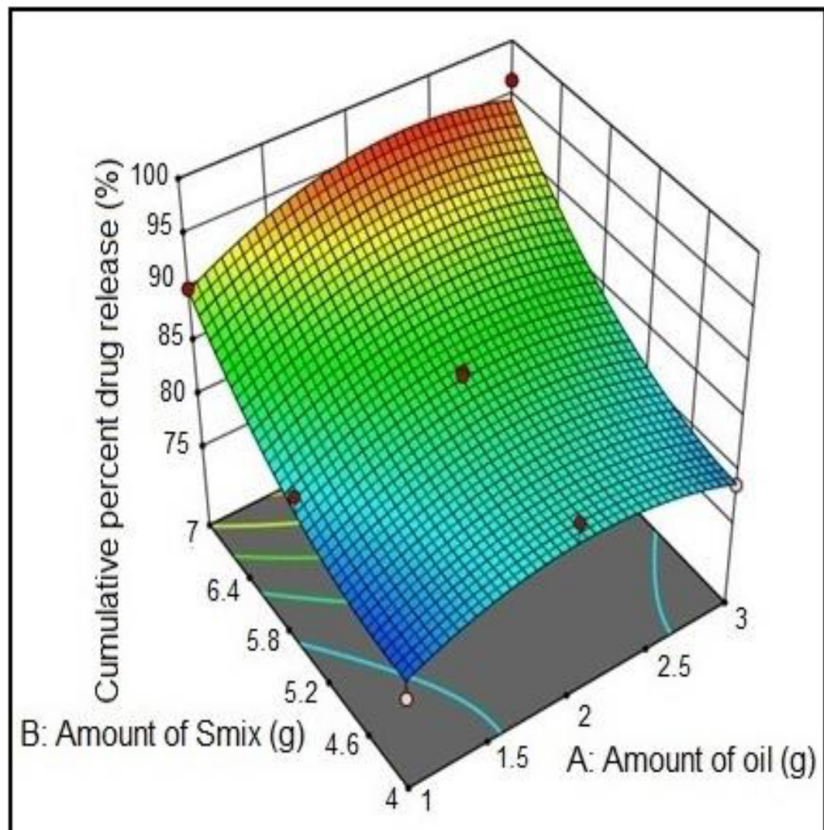

Figure 4: Response surface plot for cumulative percent drug release $(n=3$, mean $\pm S D)$.

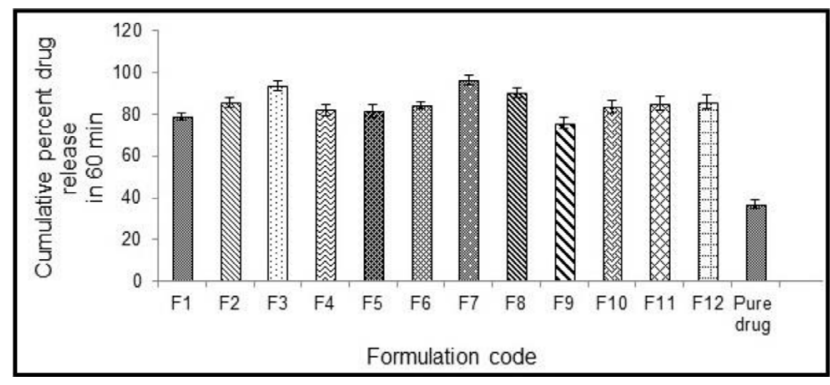

Figure 5: In vitro drug release of factorial batches of L-SNEDDS (in $60 \mathrm{~min}) .(n=3$, mean \pm SD).

- $96.41 \%$ in $60 \mathrm{~min}$. The terms $\mathrm{B}$ and $\mathrm{B}^{2}$ had positive coefficients $(p<0.05)$ indicating increased release with increase in amount of $S_{\text {mix }}$. The negative coefficient evident for term $\mathrm{A}$ (oil concentration) and $\mathrm{A}^{2}$ implied decrease in release with increased oil concentration. CLN is lipophilic drug $(\log P=4.6)$ and is expected to have a higher affinity for the oil phase than surrounding aqueous medium thus reducing percent drug release. ${ }^{64}$

\section{Validation of optimized batch}

Statistical optimization technique was used to develop the optimized formulation with desired responses. The constraints set for statistical optimization of L-SNEDDS were droplet size (Y1 $<100 \mathrm{~nm}$ ) and cumulative percent drug release ( $\mathrm{Y} 2>90 \%$ ). Based on these two responses three optimized batches of L-SNEDDS were identified by the software of which one batch 
was selectedbased on the desirability.The selected optimized batch of L-SNEDDS contained $S_{\text {mix }}(7 \mathrm{~g})$ (A) and oil (2.92 g) (B) exhibiting a droplet size of $23.70 \mathrm{~nm} \pm 3.45$, and cumulative percent drug release of $95.24 \% \pm 1.31$ with desirability 1 . Validation of the optimization results by comparingthe observed responses with predicted responses showed that percent prediction error for both the responses (Y1 and Y2) ranged between $0.98 \%$ and $0.99 \%$ of L-SNEDDS. Thus, the formulation batch giving minimum particle size (Y1) and the maximum cumulative percent drug release (Y2) was chosen as the optimized batch and evaluated further.

\section{Characterization of optimized batch}

\section{Self emulsification time}

Self emulsification time reflects the lag time involved in the formation of nanoemulsion wherein faster selfemulsification is desirous. In present study the optimized batch of L-SNEDDS emulsified in $34 \mathrm{~s}$. The $S_{\text {mix }}$ enhances the solubilization of CLN in water by forming surface film between oil and water. ${ }^{65}$ Higher HLB value of Cremophor RH-40 (HLB>12) means higher level of hydrophobicity which may be the reason for faster self-emulsification. ${ }^{66}$ Faster emulsification involves water penetration in oil-water interface through the mixed film layer of the $S_{\text {mix }}$, with the formation of liquid crystalline phases which results in swelling at the interface. This results in ease of emulsion formation, as indicated by the lower equilibration times. ${ }^{67}$

\section{Percent transmittance and cloud point test}

Percent transmittance of optimized L-SNEDDS after dilution with DW was found to be $98.58 \% \pm 1.24$ thusindicating that optical clarity of the optimized of L-SNEDDS was not compromised after dilution with distilled water. ${ }^{68}$ This points to the robustness of the formulation. Cloud point of the formulation was found to be $84^{\circ} \mathrm{C}$. It is a lower consulate temperature indicating inverse temperature dependency of surfactant solubility and commonly exhibited by nonionic surfactants. ${ }^{69}$ Cloud point higher than body temperature $\left(37^{\circ} \mathrm{C}\right)$ is desirable as it means that the $S_{\text {mix }}$ remains molecularly dispersed in the GI fluids at body temperature and facilitates self-emulsification..$^{70,71}$

\section{Viscosity determination}

The viscosity of SNEDDS plays an important role during its dispersion in the aqueous phase. Higher viscosities tend to slow down the emulsification rate, which may affect in vivo drug release and bioavailability profiles. ${ }^{72}$ The viscosity of the optimized L-SNEDDS formulation before and after dilution was found to be $19.56 \pm 1.01 \mathrm{cps}$ and $8.46 \pm 1.23$ cps. Lower viscosity tends to faster emulsification rate in GI tract which may increase in vivo drug release and bioavailability profiles. $^{73}$

\section{Preparation of S-SNEDDS}

Various adsorbents such as microcrystalline cellulose, Aerosil 200, $\beta-C D$ nanosponges and magnesium carbonate were investigated to prepare S-SNEDDS. S-SNEDDS overcomes the problem related to handling of L-SNEDDS such as leaching from gelatin capsules, incompatibility with soft gelatin capsules in addition to penetration into hard gelatin shells. The criteria for selection are micromeritic properties and amount of adsorbent required to form a free flowing powder (Table 2). Nanosponges formed free flowing powder in the ratio was 1:2 (L-SNEDDS Nanosponge) while with other adsorbents either a damp mass was obtained or flow ability was poor. The S-SNEDDS prepared with NS as adsorbent showed good flow property with Carr's index of 9.45, Hauser's ratio of 1.10 and angle of repose of $24.56^{\circ}$. These findings indicated a good packing ability. The drug content in solid SNEDDS was found to be $98.60 \pm 0.45 \%$. Reduction in drug

\begin{tabular}{|c|c|c|c|}
\hline $\begin{array}{l}\text { 루 } \\
\text { जे }\end{array}$ & 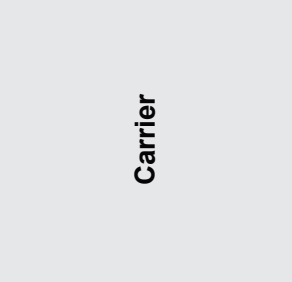 & 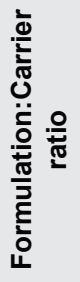 & 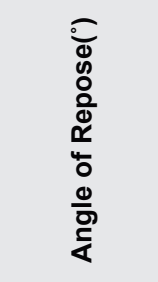 \\
\hline 1. & $\begin{array}{l}\text { Microcrystalline } \\
\text { cellulose }\end{array}$ & $1: 3$ & 33.46 \\
\hline 2. & $\begin{array}{l}\text { Microcrystalline } \\
\text { cellulose }\end{array}$ & $1: 2$ & 31.02 \\
\hline 3. & $\begin{array}{l}\text { Microcrystalline } \\
\text { cellulose }\end{array}$ & $1: 1$ & Damp mass \\
\hline 4. & Aerosil 200 & $1: 3$ & 23.38 \\
\hline 5. & Aerosil 200 & $1: 2$ & 17.87 \\
\hline 6. & Aerosil 200 & $1: 1$ & 20.31 \\
\hline 7. & $\beta$ - CD nanosponge & $1: 3$ & 25.07 \\
\hline 8. & $\beta$ - CD nanosponge & $1: 2$ & 24.56 \\
\hline 9. & $\beta-C D$ nanosponge & $1: 1$ & Damp mass \\
\hline 10. & Magnesium carbonate & $1: 3$ & Damp mass \\
\hline 11. & Magnesium carbonate & $1: 2$ & Damp mass \\
\hline 12. & Magnesium carbonate & $1: 1$ & Damp mass \\
\hline
\end{tabular}


content after solidification can be attributed to product loss due to handling, though it is not significant. Nano sponges prepared from $\beta$-cyclodextrin are nanoporous materials used as carriers for drug delivery and as solubility enhancing agents. The hydrophobic cavities in the $\beta$-CDs plus the nan cavities created due to crosslinking act as ideal sites for adsorption of the SNEDDS.Various physical interactive forces such as van der Waals forces could play a role in adsorption of the L-SNEDDS onto $\beta$-CD nanosponges. ${ }^{74}$

\section{Powder X-ray diffractometery}

X-ray powder diffract gram for pure CLN showed sharp peaks at $2 \theta$ angles of 16.2, 19.7, 21.4, 22.93, 23.1, $24.6,25.7^{\circ}$ which indicated that drug is highly crystalline (Figure 6). The CLN in the S-SNEDDS showed no sharp peaks which proved that the drug was molecularly dispersed in the oil- $S_{\text {mix }}$ which retained its integrity even after adsorption on nanosponge. ${ }^{75}$

\section{Scanning Electron Microscopy}

The scanning electron micrographs of plain nanosponge and S-SNEDDS showed nanosponges as spherical particles with a smooth, porous surface (Figure 7). The surface of S-SNEDDS clearly showed the presence of the adsorbed material. Various physical interactive forces such as van

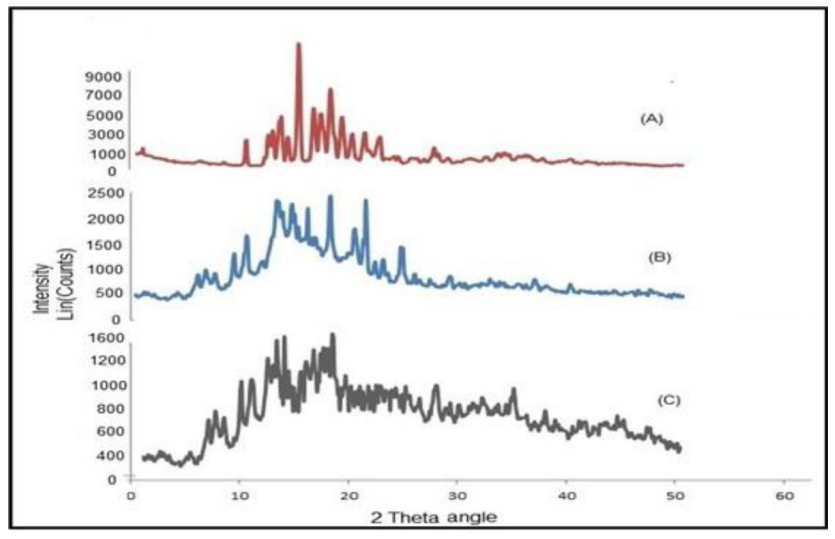

Figure 6: Powder X-ray diffractogram of pure (A) CLN, (B) Plain nanosponges and (C) Solid SNEDDS.

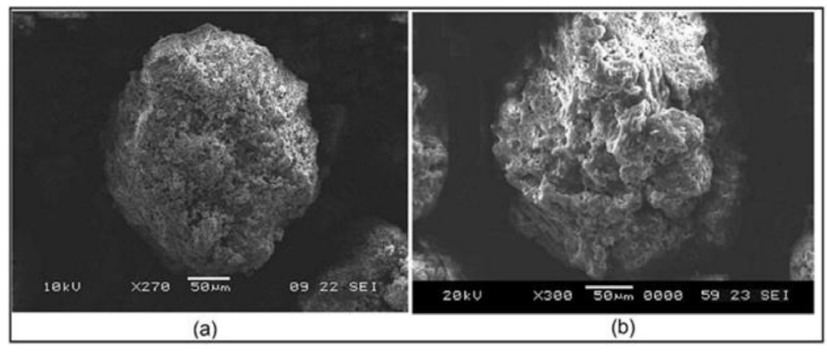

Figure 7: Scanning electron micrograph of (a) Nanosponge (b) Nanosponge + L-SNEDDS.

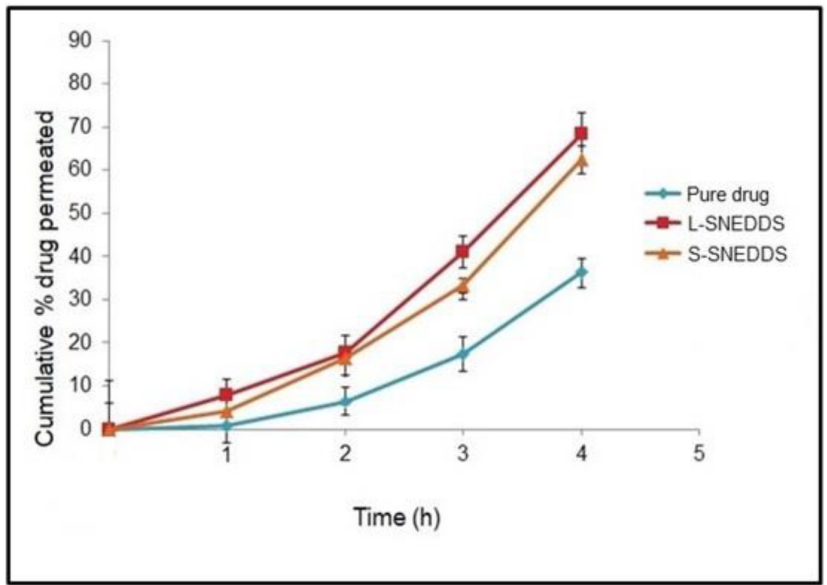

Figure 8: EX-vivo release profile of pure drug, L-SNEDDS and S- SNEDDS.

der Waals forces could play a role in the adsorption of the SNEDDS onto nanosponge. ${ }^{76}$

\section{Drug content determination}

The drug content in solid SNEDDS was found to be $98.60 \pm 0.45 \%$. Reduction in drug content after solidification can be attributed to product loss due to handling, though it is not significant. ${ }^{77}$

\section{Ex vivo permeation studies}

The ex vivo performance of pure CLN, L-SNEDDS and S-SNEDDS was determined using everted intestine sac method in terms of flux $\left(\mu \mathrm{g} / \mathrm{min} / \mathrm{cm}^{2}\right)$ and apparent permeability $(\mathrm{cm} / \mathrm{s})$. Percent drug permeated through goat intestinal membrane for pure drug, L-SNEDDS and S-SNEDDS was found to be 36.3, 68.22 and $62.39 \%$ in $4 \mathrm{~h}$ respectively (Figure 8). L-SNEDDS formulations exhibited 1.84 times higher flux and 3.8 times higher apparent permeability than pure drug. However, S-SNEDDS exhibited 1.38 times increase in flux and 3.1 times increase in apparent permeability than pure drug. ${ }^{78}$ These outcomes support the enhanced permeation properties of CLN in the form of L-SNEDDS and S-SNEDDS formulation. The increase in the apparent permeability (Papp) of L-SNEDDScouldbe due to smaller droplet size of L-SNEDDS. These smaller sized droplets containing solubilized CLNeasily permeated across the barrier membrane that probably enhances flux and apparent permeability of CLN from SNEDDS. The reduced Papp of S-SNEDDS as compared with L-SNEDDS results due to time lag involved in drug release from nanosponges. The oil-filled micelles of the $S_{\text {mix }}$ which are formed in vivo, can be presumed to cross the intestinal barrier, akin to movement of chylomicrons which are responsible for transport of fats and oils through the enterocytes 
which then enter the intestinal lymphatic system. ${ }^{79}$ Additionally the small droplet size of the nanoemulsion resulted in enhanced transport of the drug and optimized its intestinal absorption and permeation. ${ }^{80}$

\section{In vivo pharmacokinetic studies}

The comparative analysis of pharmacokinetic parameters for optimized L-SNEDDS and plain drug suspension was done. Nearly 5.53 folds increase in $\mathrm{AUC}_{0-\infty}$ of optimized L-SNEDDS was observed compared to CLN which can be credited to increase in solubility and dissolution rate. A 3.2 times increase in $\mathrm{C}_{\max }$ was observed whereas the $\mathrm{T}_{\max }$ was $2.5 \mathrm{~h}$ for the L-SNEDDS, slightly slower than for plain drug (Table 3 ). Graph pad prism 8 software was used to statistically validate the results. Analysis of variance (ANOVA) was used to find out significant differences in 2 groups (standard and test). The probability ( $p$ - value) was below 0.05 indicating that there was significant difference in pharmacokinetics of the formulations. We may presume that major fraction of CLN in the L-SNEDDS is absorbed through gut-associated lymphoid tissue consisting of isolated or aggregated lymphoid follicles that form Peyer's patches. ${ }^{81}$ The lymphatic fluids eventually drain into systemic circulation, thereby circumventing first pass metabolism. Additionally surfactants in the formulation alter the barrier properties of the intestinal mucosa and enhance its permeability by suppressing the polarized efflux system leading to increase in extent of drug absorption. ${ }^{82}$ Mishra et al. ${ }^{24}$ reported 2.5 fold increase in bioavailability of CLN polymeric nanoparticles prepared using poly lacticglycolic acid. Polymeric nanoparticles are absorbed by generic route of GI absorption and hence the higher bioavailability of CLN with SNEDDS canbe attributed to lymphatic uptake of the drug.

\section{Tissue distribution study}

In these studies, standard (CLN suspension) and test (CLN L-SNEDDS) concentration in lymph node, liver

\section{Table 3: Pharmacokinetic parameters of plain CLN and L-SNEDDS. ( $n=3$, mean \pm SD).}

\begin{tabular}{|c|c|c|}
\hline Parameters & Plain Drug CLN & $\begin{array}{c}\text { Optimized batch of } \\
\text { L-SNEDDS }\end{array}$ \\
\hline $\mathrm{C}_{\max }(\mu \mathrm{g} / \mathrm{ml})$ & $3.57 \pm 0.001$ & $10.90 \pm 0.002$ \\
\hline $\mathrm{T}_{\max }(\mathrm{h})$ & 2 & 2.5 \\
\hline $\mathrm{AUC}_{0-4 \mathrm{~h}}$ & 9.8324 & 33.96355 \\
\hline $\mathrm{AUC}_{0-\infty}$ & 12.3654 & 68.4916 \\
\hline $\begin{array}{c}\text { ANOVA (Paired } \\
\text { t-test: } \\
\text { One tailed) }\end{array}$ & $\begin{array}{c}\text { Significant } \\
\text { (p-value: } 0.003)\end{array}$ & \\
\hline
\end{tabular}

Table 4: Tissue distribution studies in rats.

\begin{tabular}{|c|c|c|}
\hline \multirow{2}{*}{ Name of organ } & \multicolumn{2}{|c|}{ Concentration of CLN $(\boldsymbol{\mu g} / \mathrm{ml})$} \\
\cline { 2 - 3 } & $\begin{array}{c}\text { Standard } \\
\text { (Plain drug suspension) }\end{array}$ & $\begin{array}{c}\text { Test } \\
\text { (L-SNEDDS) }\end{array}$ \\
\hline Lymph nodes & 0.3510 & 0.4054 \\
\hline Kidney & 0.9292 & 0.4021 \\
\hline Liver & 1.2753 & 0.5481 \\
\hline
\end{tabular}

and kidneys were measured $2 \mathrm{~h}$ after oral administration to rats. Organs were homogenized, extracted with mobile phase (Methanol: Acetonitrile 50:50\% v/v) and then analyzed by bio analytical HPLC method. ${ }^{79} \mathrm{CLN}$ reportedly undergoes extensive hepatic first pass metabolism resulting in $80 \%$ of its dose being eliminated through feces in its inactive form ${ }^{52}$. The concentration of CLN in the lymph nodes was found to be significantly higher than that of pure drug suspension, thus corroborating the in vivo findings (Table 4). In addition, the oil ingredients of the L-SNEDDS would presumably facilitate the association of CLN with chylomicrons, leading to enhanced lymphatic absorption of the drug. ${ }^{83}$

\section{Stability studies}

The optimized L-SNEDDS was subjected to physical and chemical stability studies at $40^{\circ} \mathrm{C} \pm 75 \% \mathrm{RH}$ for 3 months and evaluated at intervals of $0,1,2$, and 3 months. During the period of study, no change in physical and chemical properties of optimized batch of L-SNEDDS was observed. A marginal increase in particle size was seen after 3 months whereas a nominal change was observed in PDI and zeta potential.

\section{CONCLUSION}

Solid self nano-emulsifying drug delivery system of Cilnidipine was prepared to improve its oral bioavailability. Capmul PG8 NF, Cremophor RH 40 and Transcutol HP were used as oil and surfactants. A $3^{2}$ factorial design was used to study effect of formulation variables on key properties. The optimized batch displayed nanometer droplet size and good selfemulsifying ability. In vivo studies revealed improved pharmacokinetic properties which were attributed to greater surface area and lymphatic absorption thus circumventing hepatic first pass metabolism.

\section{ACKNOWLEDGEMENT}

The authors would like to thank Dr. Ashwini Madgulkar, Principal, AISSMS College of Pharmacy, Pune, India for providing necessary facilities to carry out the research work. 


\section{CONFLICT OF INTEREST}

The authors declare that they have no conflict of interest, financial or otherwise, to disclose.

\section{ABBREVIATIONS}

CLN: Cilnidipine; GIT: Gastro Intestinal Tract; SNEDDS: Self nano-emulsifying drug delivery systems; LFCS: Lipid formulation classification system; BCS: Biopharmaceutical classification system.

\section{REFERENCES}

1. Shaikh. Permeability enhancement techniques for poorly permeable drugs: a review. J App Pharm Sci. 2012;2(7):34-9. doi: 10.7324/JAPS.2012.2705.

2. Serajuddin AT. Salt formation to improve drug solubility. Adv Drug Deliv Rev. 2007;59(7):603-16. doi: 10.1016/j.addr.2007.05.010, PMID 17619064.

3. Patil S, Wagh K, Parik V, Akarte A, Baviskar D. Strategies for solubility enhancement of poorly soluble drugs. Int J Pharm Sci Rev Res. 2011;8(2):74-80.

4. Mehta S, Joseph NM, Feleke F, Palani S. Improving solubility of BCS class II drugs using solid dispersion: a review. J Drug Delivery Ther. 2018;4(3):7-13. doi: 10.22270/jddt.v4i3.844.

5. Choudhari V, Patel J. Cyclodextrin inclusion complex to enhance solubility of poorly water soluble drugs: a review. Int J Pharm Sci Res. 2013;4(1):68-76.

6. Kothawade S, Pacharne V. Formulation and evaluation of liquid and solid self micro emulsifying. Int J Pharm Sci Res. 2018;9(12):5333-8.

7. Yang T, Cui FD, Choi MK, Lin H, Chung SJ, Shim CK, Kim DD. Liposome formulation of paclitaxel with enhanced solubility and stability. Drug Deliv. 2007;14(5):301-8. doi: 10.1080/10717540601098799, PMID 17613018.

8. Sheikh Z, Morshed N. Optimizing oral drug delivery using lipid based formulations. Int Res J Pharm. 2014;5(7):514-22. doi: 10.7897/2230-8407.0507105.

9. Pouton CW, Porter CJ. Formulation of lipid-based delivery systems for oral administration: materials, methods and strategies. Adv Drug Deliv Rev. 2008;60(6):625-37. doi: 10.1016/j.addr.2007.10.010, PMID 18068260.

10. Basalious EB, Shawky N, Badr-Eldin SM. SNEDDS containing bioenhancers for improvement of dissolution and oral absorption of lacidipine. I: development and optimization. Int J Pharm. 2010;391(1-2):203-11. doi: 10.1016/j.jpharm.2010.03.008, PMID 20214965.

11. Senapati PC, Sahoo SK, Sahu AN. Mixed surfactant based (SNEDDS) selfnanoemulsifying drug delivery system presenting efavirenz for enhancement of oral bioavailability. Biomed Pharmacother. 2016;80:42-51. doi: 10.1016/j. biopha.2016.02.039, PMID 27133038.

12. Seo YG, Kim DH, Ramasamy T, Kim JH, Marasini N, Oh YK, Kim DW, Kim JK, Yong CS, Kim JO, Choi HG. Development of docetaxel-loaded solid self-nanoemulsifying drug delivery system (SNEDDS) for enhanced chemotherapeutic effect. Int J Pharm. 2013;452(1-2):412-20. doi: 10.1016/j. ijpharm.2013.05.034, PMID 23707964.

13. Hashem FM, Al-Sawahli MM, Nasr M, Ahmed OA. Custom fractional factorial designs to develop atorvastatin self-nanoemulsifying and nanosuspension delivery systems - enhancement of oral bioavailability. Drug Des Devel Ther. 2015;9:3141-52. doi: 10.2147/DDDT.S86126, PMID 26150693.

14. Patel J, Kevin G, Patel A, Raval M, Sheth N. Design and development of a self-nanoemulsifying drug delivery system for telmisartan for oral drug delivery. Int J Pharm Investig. 2011;1(2):112-8. doi: 10.4103/2230973X.82431, PMID 23071930.

15. Tiwari G, Rai A, Tiwari R. Self-emulsifying drug delivery system: an approach to enhance solubility. Syst Rev Pharm. 2010;1(2):133-40. doi: 10.4103/09758453.75055.

16. Prajapati ST, Joshi HA, Patel CN. Preparation and Characterization of Self-Microemulsifying Drug Delivery System of Olmesartan Medoxomil for Bioavailability Improvement. J Pharm (Cairo). 2013;2013:728425. doi: 10.1155/2013/728425. PMID 26555991.

17. Lei Y, Lu Y, Qi J, Nie S, Hu F, Pan W, Wu W. Solid self-nanoemulsifying cyclosporin a pellets prepared by fluid-bed coating: preparation, characterization and in vitro redispersibility. Int J Nanomedicine. 2011;6:795805. doi: 10.2147/IJN.S17711, PMID 21589647.

18. Rashid R, Kim DW, Yousaf AM, Mustapha O, Fakhar Ud Din, Park JH, Yong CS, Oh YK, Youn YS, Kim JO, Choi HG. Comparative study on solid self-nanoemulsifying drug delivery and solid dispersion system for enhanced solubility and bioavailability of ezetimibe. Int J Nanomedicine. 2015;10:6147-59. doi: 10.2147/IJN.S91216, PMID 26491288.

19. Abbaspour M, Jalayer N, Sharif Makhmalzadeh BS. Development and evaluation of a solid self-nanoemulsifying drug delivery system for loratadin by extrusion-spheronization. Adv Pharm Bull. 2014;4(2):113-9. doi: 10.5681/ apb.2014.018, PMID 24511474.

20. Weerapol Y, Limmatvapirat S, Nunthanid J, Sriamornsak P. Selfnanoemulsifying drug delivery system of nifedipine: impact of hydrophiliclipophilic balance and molecular structure of mixed surfactants. AAPS PharmSciTech. 2014;15(2):456-64. doi: 10.1208/s12249-014-0078-y, PMID 24452500

21. Pansuriya $\mathrm{V}$, Bhandari A. Formulation and optimization of press coated pulsatile tablet of cilnidipine for Chronopharmaceutical approach for treatment of hypertension. Int J Pharm Pharmceu Res. 2015;3(2):169-82.

22. Hu L, Song W, Niu F, Jiao K, Jia Z. Preparation, characterization and tableting of cilnidipine solid dispersions. Pak J Pharm Sci. 2013;26(3):629-36. PMID 23625441.

23. Siju VV, Soniwala M, Nagar S. A novel technique to enhance dissolution rate of cilnidipine using liquisolid compact and wet granulation. Int J Pharm Sci and Drug Res. 2017;9(4):160-8. doi: 10.25004/IJPSDR.2017.090402.

24. Mishra R, Mir SR, Amin S. Polymeric nanoparticles for improved bioavailability of cilnidipine. Int J Pharm Pharm Sci. 2017;9(4):129-39. doi: 10.22159/ ijpps.2017v9i4.15786.

25. Tandel H, Raval K, Nayani A, Upadhay M Preparation and evaluation of cilnidipine microemulsion. J Pharm Bioallied Sci. 2012;4(Suppl 1):S114-5. doi: 10.4103/0975-7406.94162. PMID 23066184.

26. Bhalerao A, Chaudhari PP. Formulation of solid lipid nanoparticles of cilnidipine for the treatment of hypertension. J Drug Delivery Ther. 2019;9(3):212-21. doi: 10.22270/jddt.v9i3.2849.

27. Bakhle SS, Avari JG. Development and characterization of solid selfemulsifying drug delivery system of cilnidipine. Chem Pharm Bull (Tokyo). 2015;63(6):408-17. doi: 10.1248/cpb.c14-00326, PMID 26027464.

28. Hyma P. Formulation and characterization of novel self micro emulsifying drug delivery system of glimepiride. Int J Sci Technol. 2014;24(1):1640-448.

29. Avachat AM, Patel VG. Self nanoemulsifying drug delivery system of stabilized ellagic acid-phospholipid complex with improved dissolution and permeability. Saudi Pharm J. 2015;23(3):276-89. doi: 10.1016/j. jsps.2014.11.001, PMID 26106276.

30. Rao MRP, Bhutada K, Kaushal P. Taste evaluation by electronic tongue and bioavailability enhancement of efavirenz. AAPS PharmSciTech. 2019;20(2):56. doi: 10.1208/s12249-018-1277-8, PMID 30617434.

31. Kamble RN, Mehta PP, Kumar A. Efavirenz self-nano-emulsifying drug delivery system: in vitro and in vivo evaluation. AAPS PharmSciTech. 2016;17(5):1240-7. doi: 10.1208/s12249-015-0446-2, PMID 26573159.

32. Patel G, Shelat P, Lalwani A. Statistical modeling, optimization and characterization of solid self-nanoemulsifying drug delivery system of lopinavir using design of experiment. Drug Deliv. 2016;23(8):3027-42. doi: 10.3109/10717544.2016.1141260, PMID 26882014.

33. Ghori V, Patel D, Omri A. Formulation and optimization of self Nano emulsifying drug delivery system of lercanidipine hydrochloride using response surface methodology. Int J Pharm Res and Bio Sci. 2017;6(4):162-76.

34. Narkhede R, Gujar K, Gambhire V. Design and evaluation of selfnanoemulsifying drug delivery systems for nebivolol hydrochloride. Asian J Pharm. 2014;4(2):224-37.

35. Patel J, Patel A, Raval M, Sheth N. Formulation and development of a selfnanoemulsifying drug delivery system of irbesartan. J Adv Pharm Technol Res. 2011;2(1):9-16. doi: 10.4103/2231-4040.79799, PMID 22171286.

36. Bakhle S, Avari J. Development and evaluation of liquid and solid selfmicroemulsifying drug delivery system of lovastatin. Asian J Pharm. 2016;10(1):22-35.

37. Miryala V, Kurakula M. Self-Nano emulsifying drug delivery system (SNEDDS) for oral delivery of atorvastatin-formulation and bioavailability studies. J Drug Deliv Ther. 2013;3(3):131-42. 
38. Nasr AM, Gardouh AR, Ghonaim HM, Ghorab MM. Design, formulation and in-vitro characterization of irbesartan solid self-nanoemulsifying drug delivery system (S-SNEDDS) prepared using spray drying technique. J Chem Pharm Res. 2016;8(2):159-83.

39. Rao M, Raut S, Shirsath C, Jadhav M, Chandanshive P. Self-nanoemulsifying drug delivery system of mebendazole for treatment of lymphatic filariasis. Indian J Pharm Sci. 2019;80(6):1057-68.

40. Reddy S, Bunga R, Vijetha K. Development and evaluation of solid self Nano emulsifying drug delivery system of poorly soluble olmesartan medoxomil by using adsorption on to solid carrier technique. Int $\mathrm{J}$ Pharm Sci Res. 2018;9(8):3398-407.

41. Beg S, Swain S, Singh HP, Patra ChN, Rao ME. Development, optimization, and characterization of solid self-nanoemulsifying drug delivery systems of valsartan using porous carriers. AAPS PharmSciTech. 2012;13(4):1416-27. doi: 10.1208/s12249-012-9865-5, PMID 23070560.

42. Shanmugam S, Baskaran R, Balakrishnan P, Thapa P, Yong CS, Yoo BK. Solid self-nanoemulsifying drug delivery system (S-SNEDDS) containing phosphatidylcholine for enhanced bioavailability of highly lipophilic bioactive carotenoid lutein. Eur J Pharm Biopharm. 2011;79(2):250-7. doi: 10.1016/j. ejpb.2011.04.012, PMID 21550401.

43. Reddy M, Sravanthi B. Formulation and in vitro characterization of solidself nanoemulsifying drug delivery system of atorvastatin calcium. Asian J Pharm. 2017;11(4):S991-9.

44. Mohd AA, Fahad IJ, Abdullah M. Everted gut sac model as a tool in pharmaceutical research: limitations and applications. J Pharm Pharmacol. 2012;64:326-36.

45. Liu W, Pan H, Zhang C, Zhao L, Zhao R, Zhu Y, Pan W. Developments in methods for measuring the intestinal absorption of nanoparticle-bound drugs. Int J Mol Sci. 2016;17(7):1171-91. doi: 10.3390/ijms17071171, PMID 27455239.

46. Nasr A, Gardouh A, Ghorab M. Novel solid self-nanoemulsifying drug delivery system (s-snedds) for oral delivery of olmesartan medoxomil: design, formulation, pharmacokinetic and bioavailability evaluation. Pharmaceutics. 2016;8(3):1-29. doi: 10.3390/pharmaceutics8030020, PMID 27355963.

47. Rao JV, Reddy TRM. Self nanoemulsifying drug delivery system of candesartan cilexetil with improved bioavailability. Int J Pharm Sci and Drug Res. 2019;10(5):351-61. doi: 10.25004/IJPSDR.2018.100501.

48. Hung WL, Chang WS, Lu WC, Wei GJ, Wang Y, Ho CT, Hwang LS. Pharmacokinetics, bioavailability, tissue distribution and excretion of tangeretin in rat. J Food Drug Anal. 2018;26(2):849-57. doi: 10.1016/j. jfda.2017.08.003, PMID 29567257.

49. Reddy B, Md Fazal Ul-Haq. Formulation and in-vitro characterization of solid - self nanoemulsifying drug delivery system (S-SNEDDS) of rilpivirine. Int $\mathrm{J}$ Pharm Sci Res. 2016;7(7):3117-29.

50. Singh B, Khurana L, Bandyopadhyay S, Kapil R, Katare OO. Development of optimized self-nano-emulsifying drug delivery systems (SNEDDS) of carvedilol with enhanced bioavailability potential. Drug Deliv. 2011;18(8):599-612. doi: 10.3109/10717544.2011.604686, PMID 22008038.

51. Patel V, Desai T, Kapupara P, Atara S, Keraliya R. Self emulsifying drug delivery system: a conventional and alternative approach to improve oral bioavailability of lipophilic drugs. Int J Drug Dev Res. 2010;2(4):859-70.

52. [cited Jul 5]Available from: https://www.drugbank.ca/drugs/DB09232; 2020.

53. Madhavi K, Shikha A, Yadav J. Self Nano emulsifying drug delivery system of ramipril: formulation and in vitro evaluation. Int $\mathrm{J}$ Pharm Pharm Sci. 2016;8(4):291-6.

54. Nanjwade BK, Patel DJ, Udhani RA, Manvi FV. Functions of lipids for enhancement of oral bioavailability of poorly water-soluble drugs. Sci Pharm. 2011;79(4):705-27. doi: 10.3797/scipharm.1105-09, PMID 22145101.

55. Prajapati H, Patel D, Patel N, Dalrympl D, Serajuddin A. Effect of difference in fatty acid chain lengths of medium-chain lipids on lipid-surfactant-water phase diagrams and drug solubility. J Excipients Food Chem. 2011;2(3):73-88.

56. Dash RN, Mohammed H, Humaira T, Ramesh D. Design, optimization and evaluation of glipizide solid self-nanoemulsifying drug delivery for enhanced solubility and dissolution. Saudi Pharm J. 2015;23(5):528-40. doi: 10.1016/j. jsps.2015.01.024, PMID 26594119.

57. Thakare P, Mogal V, Borase P, Dusane J, Kshirsagar S. A review on selfemulsified drug delivery system. Pharm and Bio Eval. 2016;3(2):1-8.
58. Sharma AK, Garg T, Goyal AK, Rath G Role of microemuslsions in advanced drug delivery. Artif Cells Nanomed Biotechnol. 2016;44(4):1177-85. doi: 10.3109/21691401.2015.1012261. PMID 25711493.

59. Patel S, Parikh J. Preparation and in-vitro characterization of crystallo-coagglomerates of cilnidipine. J Pharm Innov. 2016;3(13):12-20.

60. Shafiq-un-Nabi S, Shakeel F, Talegaonkar S, Ali J, Baboota S, Ahuja A, Khar RK, Ali M. Formulation development and optimization using nanoemulsion technique: a technical note. AAPS PharmSciTech. 2007;8(2):Article 28. doi: 10.1208/pt0802028, PMID 17622106.

61. Yadav P, Yadav E, Verma A, Amin S. Evaluation of hydrochlorothiazide loaded self-nanoemulsifying drug delivery systems. Sci World J. 2014;2014:1-10.

62. Zanchetta B, Chaud M, Helena M. SEDDS: nanocarrier system for a new cardiac dysfunction drug. Eur J Biomed and Pharm Sci. 2015;2(7):96-111.

63. Tharwat F. Surfactants as dispersants and stabilization of suspensions: applied surfactants; Principles and applications, Wiley $-\mathrm{VCH}$ verglagGmbt\&Co. KGaA. Weinhein. 2005;14:3-46.

64. Panner S, Kulkarni P, Dixit M. Preparation and evaluation of selfnanoemulsifying formulation of efavirenz. Ind $\mathrm{J}$ Pharm Edu Res. 2013;47(1):47-54

65. Kavitha K. Solubility enhancement-a challenge for hydrophobic drugs. IOSR JPBS. 2015;10(6):50-60.

66. Nasr A, Gardouh A, Ghonaim H, Abdelghany E, Ghorab M. Effect of oils, surfactants and cosurfactants on phase behavior and physicochemical properties of self-nanoemulsifying drug delivery system (SNEDDS) for irbesartan and olmesartan. Int J Appl Pharm. 2016;8(1):13-24.

67. Singh A, Singh V, Rawat G, Juyal D. Self emulsifying systems: a review. Asian J Pharm. 2015;9(1):13-8. doi: 10.4103/0973-8398.150031.

68. Patil P, Kate V, Payghan S. Potential investigation of Peceol for formulation of ezetimibe self nanoemulsifying drug delivery systems. Asian J Biomed and Pharm Sci. 2016;6(54):21-32.

69. Sinko PJ. Solubility and distribution phenomenon: Martin's Physical Pharmacy and Pharmaceutical Sciences. 5th ed,Lippincott Willams and Wilkins, a Wolters Kluwer Business, Baltimore,MD; 2016.

70. Kovvasu S, Kunamaneni P, Joshi R, et al. Self-emulsifying drug delivery systems and their marketed products: a review. Asian J Pharm. 2019;13(2):73-84.

71. Akula S, Gurram AK, Devireddy SR Self-Microemulsifying Drug Delivery Systems: An Attractive Strategy for Enhanced Therapeutic Profile. Int Sch Res Notices. 2014;2014:964051. doi: 10.1155/2014/964051. PMID 27382619.

72. Patil $P$, Joshi $P$, Paradkar A. Effect of formulation variables on preparation and evaluation of gelled Self-Emulsifying Drug Delivery System (SEDDS) of ketoprofen. AAPS PharmSciTech. 2004;5(3):e42. doi: 10.1208/pt050342, PMID 15760075.

73. Tanya M, SMEDDS/SNEDDS. An emerging technique to solubility enhancement for the pharmaceutical industry. World J Pharm Pharm Sci. 2017;6(7):317-36.

74. Suvarna V, Pagdhare U, Kadu A, Oza M. Development and characterization of solid self-emulsifying drug delivery system containing nateglinide. Asian $\mathrm{J}$ Pharm. 2017;11(1):27-36.

75. Akhter MH, Ahmad A, Ali J, Mohan G. Formulation and development of coq10-loaded s-snedds for enhancement of oral bioavailability. J Pharm Innov. 2014;9(2):121-31. doi: 10.1007/s12247-014-9179-0.

76. Abd-Elhakeem E, Teaima MH, Abdelbary GA, El Mahrouk GM. Bioavailability enhanced clopidogrel -loaded solid SNEDDS: development and in-vitrol in-vivo characterization. J Drug Deliv Sci Technol. 2019;49:603-14. doi: 10.1016/j.jddst.2018.12.027.

77. Gadhave R, Tarkase K. Formulation and evaluation of novel lipid based solidself nanoemulsifying drug delivery system of agomelatine. World J Pharm Pharm Sci. 2018;7(6):1209-24.

78. Gamal W, Fahmy RH, Mohamed MI. Development of novel amisulprideloaded liquid self-nanoemulsifying drug delivery systems via dual tackling of its solubility and intestinal permeability. Drug Dev Ind Pharm. 2017;43(9):1530-8. doi: 10.1080/03639045.2017.1322607, PMID 28447878.

79. Reddy LH, Murthy RS. Lymphatic transport of orally administered drugs. Indian J Exp Biol. 2002;40(10):1097-109. PMID 12693689. 
80. Khan B, Akhtar N, Khan S, Waseem K, Mahmood T, Rasul A, Iqbal M, Khan H. Basics of pharmaceutical emulsions: a review. Afr $\mathrm{J}$ Pharm Pharmacol. 2011;5(25):2715-25.

81. Ali Khan A, Mudassir J, Mohtar N, Darwis Y. Advanced drug delivery to the lymphatic system: lipid-based nanoformulations. Int $\mathrm{J}$ Nanomedicine. 2013;8:2733-44. doi: 10.2147/IJN.S41521, PMID 23926431.

82. Jha SK, Karki R, Puttegowda VD, Harinarayana D. In Vitro Intestinal Permeability Studies and Pharmacokinetic Evaluation of Famotidine
Microemulsion for Oral Delivery. Int Sch Res Notices. 2014;2014:452051. doi: 10.1155/2014/452051. PMID 27379272.

83. Jo K, Kim H, Khadka P, Jang T, Kim SJ, Hwang SH, Lee J Enhanced intestinal lymphatic absorption of saquinavir through supersaturated selfmicroemulsifying drug delivery systems. Asian J Pharm Sci. 2020;15(3):336-46. doi: 10.1016/j.ajps.2018.11.009. PMID 32636951.

\section{PICTORIAL ABSTRACT}

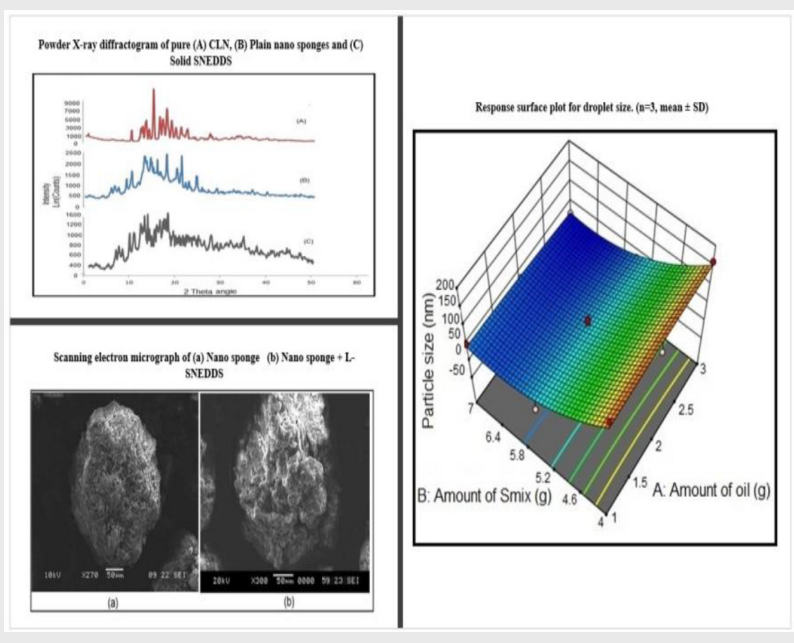

About Authors

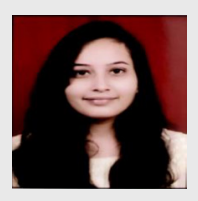

Sayali Sugaonkar, M.Pharm, Department of Pharmaceutics, AISSMS College of Pharmacy.

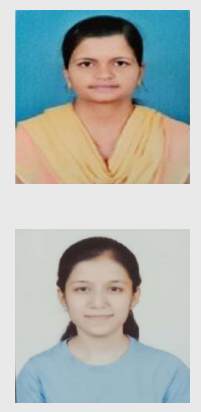

Sayali Kulkarni, Lecturer, Eklavya College of Pharmacy, Sangli.

Ashwini Sonawane, M.Pharm, Department of Pharmaceutics, AISSMS College of Pharmacy.

\section{SUMMARY}

Lipid based drug delivery systems are gaining lot of popularity worldwide to overcome many challenges associated with physico-chemical properties and biological properties of drugs and can be used to circumvent first pass metabolism and for targeted drug delivery. Self nano emulsifying drug delivery systems are easy to process and manufacture. Conversion into solid self nano-emulsifying drug delivery system enables ease of handling. In the present study SNEDDS of Cilnidipine was prepared to improve its oral bioavailability. A 32 factorial design was used to study effect of formulation variables on key properties and to derive the optimized formula. Adsorption onto nanosponges effectively converted liquid SNEDDS into solid state with required micromeritic properties. The improved pharmacokinetic profile of cilnidipine was confirmed by in vivo studies which can be attributed to greater surface area and lymphatic absorption thus circumventing hepatic first pass metabolism.

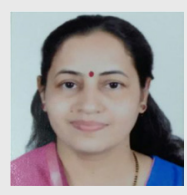

Dr. Monica RP Rao, Associate Professor, Department of Pharmaceutics, AISSMS College of Pharmacy. With 23 years of teaching and research experience, she has more than 75 publications in international and national peer reviewed journals. Her fields of interest are solubility enhancement and novel drug delivery systems. She is an avid blogger having her own blog site.

Cite this article: Rao MRP, Kulkarni S, Sonawane A, Sugaonkar S. Self-nanoemulsifying Drug Delivery System of Cilnidipine. Indian J of Pharmaceutical Education and Research. 2021;55(3):664-76. 